\title{
El derecho que sigue naciendo del pueblo: movimientos sociales y pluralismo jurídico \\ DE JESÚS ANTONIO DE LA TORRE RANGEL, MÉXICO, COYOCÁN, 2012
}

\author{
José Jesús SORIANO FLORES ${ }^{1}$
}

Los fenómenos jurídicos que aparecen formalmente reconocidos en los Estados de Derecho contemporáneos, generalmente no definen ni integran la totalidad del Derecho vigente. Una visión sesgada, es entonces la que cotidianamente se estudia académicamente, se interpreta jurisdiccionalmente, y se ejerce por la mayoría de las y los juristas.

Existe por tanto, una necesidad imperante (y urgente) de revisar con seriedad y rigor científico una concepción integral del Derecho como la que sugiere virtuosamente el libro: "El Derecho que sigue naciendo del pueblo" del destacado profesor Doctor Jesús Antonio de la Torre Rangel, ${ }^{2}$ que expone con detalle una visión crítica del universo jurídico que da continuidad a un diverso texto del autor publicado por primera vez hace casi tres décadas: "El Derecho que nace del pueblo". ${ }^{3}$

Estamos frente a una obra que aborda con experiencia, y un desarrollo intelectual, continuo y permanente, tópicos alrededor de diversos movimientos sociales, desde la óptica del pluralismo jurídico. En palabras de su autor, el libro trata bajo la perspectiva del iusnaturalismo histórico, "de un Derecho inserto en un proceso libera dor, producido tanto por movimientos sociales populares, por un lado; y por otro, producido por gobiernos, en concreto el de Bolivia, que con su nueva Carta Fundamental está creando un nuevo paradigma constitucional". ${ }^{4}$

Hay un punto de partida que establece el texto, que no solamente tiene que ver con problemáticas jurídicas, sino incluso con aspectos fundamentalmente económicos y políticos, nos referimos a la alienación política, económica y cultural, "que acarrea el hambre, la incultura,

\footnotetext{
${ }^{1}$ Profesor Investigador del Departamento de Derecho de la División de Derecho, Política y Gobierno de la Universidad de Guanajuato. Miembro del Cuerpo Académico: Ciencia Penal, Estado de Derecho y Derechos Humanos.

Doctorante en Derecho en el Programa Interinstitucional de las Universidades de la Región Centro Occidente de ANUIES; Maestro en Derecho Constitucional por la Universidad Iberoamericana y el Instituto de Investigaciones Jurídica de la UNAM. Licenciado en Derecho por la Universidad de Guanajuato.

${ }^{2}$ Doctor en Filosofía por la UNAM, Abogado egresado de la Escuela libre de Derecho, y actualmente Profesor Investigador de la Universidad Autónoma de Aguascalientes, y de posgrado de las Universidades Autónoma de San Luis Potosí e Iberoamericana, así como del Doctorado Interinstitucional en Derecho de la Región Centro Occidente de ANUIES. Es Investigador Nacional nivel II, y ha participado como docente y conferencista invitado en Universidades de Brasil, España, Colombia, Bolivia y Puerto Rico. Ha escrito múltiples libros y artículos jurídicos, y es Director del Consejo Editorial de la Revista de Derechos Humanos y Estudios Sociales (redhes).

${ }^{3}$ DE LA TORRE RANGEL, Jesús Antonio, El derecho que nace del pueblo, $1^{\text {a }}$ ed., Porrúa (en esta editorial), México, 2005.

${ }^{4}$ DE LA TORRE RANGEL, Jesús Antonio, El derecho que sigue naciendo del pueblo: movimientos sociales y pluralismo jurídico, $1^{\mathrm{a}}$ ed., Ediciones Coyoacán, México, 2012, p. 1.
} 
la sumisión y la vida indigna de la mayoría de los seres humanos; la concentración en unos cuantos, de los bienes productivos y de los de consumo, y la opresión política que hace que sólo unos decidan sobre las cuestiones importantes de la vida de los seres humanos en sociedad, dejando a la mayoría sin decir ni plasmar materialmente su palabra". Podríamos decir que estamos ante Estados que no son auténticamente democráticos, que provocan injusticia y que dan lugar a un "derecho que nace y sigue naciendo del pueblo", frase categórica que el Doctor De la Torre utiliza como corolario de las ideas que empapan sus palabras, y que desarrolla refiriendo diversos movimientos sociales contemporáneos en América Latina.

La primera parte, contiene un espacio teórico relativo al "pluralismo jurídico", que como comenta el autor, al separarse de la teoría univocista del Derecho, provoca un rompimiento epistemológico, pues acepta la diversidad y pluralidad jurídica con una racionalidad analógica en la que el ingrediente principal es la justicia. Cita a Wolkmer, al que considera el principal teórico en la materia y desarrolla su postura, para después referir la relación entre pluralismo jurídico y derechos humanos.

Posteriormente nos recuerda el movimiento revolucionario del Ejercito Zapatista de Liberación Nacional en México, que como hemos escrito en otros momentos, es fundamental estudiarlo para entender la incorporación constitucional expresa de los derechos humanos colectivos de los pueblos indígenas en el año 2001; el contexto injusto es evidente, pues constituye una pena histórica, "que los actores políticos de la década pasada, tuvieran que haber esperado el levantamiento de un grupo armado, para anotar en sus agendas los reclamos fundamentales de los pueblos indígenas". Este es precisamente uno de los elementos del panorama que provoca, en palabras del profesor De la Torre Rangel, el derecho que sigue naciendo del pueblo, y que el libro relata en la experiencia indígena mexicana de los últimos años, donde entre otros tópicos, aborda la situación en el Estado de Oaxaca, partiendo de un movimiento social que emergió en el 2006, y que produjo la Asamblea Popular de Pueblos de Oaxaca (APPO).

Igualmente la obra aborda emblemáticos movimientos sociales de Brasil, Argentina y Bolivia, y en éste último caso, estudia la nueva Constitución de 2009 que "proclama una refundación de Bolivia y se propone construir colectivamente el Estado unitario social de derecho plurinacional comunitario", en este orden de ideas, el jurista considera que el devenir político que dio origen al texto constitucional de referencia, "es fascinante por el proceso ciudadano desde los movimientos sociales autogestivos y por la objetivización de una normatividad constitucional muy interesante, en cuanto al muy amplio reconocimiento de derechos y la refundación del Estado en el pluralismo político, económico, jurídico y cultural".

Una de las consecuencias necesarias en la consolidación del nuevo paradigma constitucional de los derechos humanos en México debe ser el entendimiento y práctica de una concepción integral de la Ciencia Jurídica; "el derecho que sigue naciendo del pueblo", abona notablemente a esta construcción epistemológica que ya no podemos (ni debemos) postergar.

\footnotetext{
${ }^{5}$ Idem.

${ }^{6}$ SORIANO FLORES, José Jesús, “Derechos Humanos de los pueblos indígenas: Algunas consideraciones del tratamiento constitucional en México", en: Nuevas Tendencias del Derecho Constitucional y Derecho Procesal Constitucional, $1^{\mathrm{a}}$ ed., Instituto de Estudio e Investigación Jurídica de Nicaragua (INEJ), Nicaragua, 2011, p. 444 .

7 DE LA TORRE RANGEL, El derecho que sigue naciendo del pueblo: movimientos sociales y pluralismo jurídico, op. cit., p. 126.

${ }^{8}$ Ibidem., p. 155.

CienCIA JuRÍDICA. Departamento de Derecho. División de Derecho Política y Gobierno, Universidad de Guanajuato - Año 3, No. 5, 2014
} 